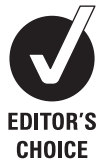

FIFA Medical Assessment and Research Centre, Zurich, Switzerland

\section{Correspondence to}

Jiri Dvorak, FIFA Medical Assessment and Research Centre, FIFA-Strasse 20, PO Box 8044, Zurich,

Switzerland;

jiri.dvorak@fifa.org

Received 29 September 2011 Accepted 30 October 2011 Published Online First 5 December 2011

\title{
Planning and implementing a nationwide football-based health-education programme
}

\author{
Jiri Dvorak, Colin W Fuller, Astrid Junge
}

\begin{abstract}
Communicable and non-communicable diseases place enormous social and economic burdens on developed and developing countries. Health education leading to changes in people's attitudes and behaviours remains the best approach for reducing the problem of communicable diseases while there is evidence that programmes providing regular physical exercise and advocating a controlled diet can reduce the prevalence of many non-communicable diseases. Hence, the delivery of health education and physical activity within a single coherent programme offers great potential for simultaneously addressing both health issues. Since 2006, FIFA has developed and tested a novel footballbased health-education programme for children entitled '11 for Health', which is aimed at increasing children's levels of physical activity while also delivering 11 simple health messages. When new interventions of this type are published in the scientific literature, it is often not possible to describe important background information about the project that could assist other researchers in developing and implementing similar programmes. This paper attempts to bridge this gap by describing the aims and objectives, organisation, planning, implementation and monitoring requirements needed to deliver FIFA's '11 for Health' programme, first as a pilot project and subsequently as a nationwide project, through a tripartite arrangement between FIFA, the national Football Association and the Government Ministries in Mauritius.
\end{abstract}

\section{INTRODUCTION}

The social and economic burden associated with communicable diseases, such as HIV/AIDS, malaria and gastrointestinal diseases, is a major concern in the developing countries of Africa. However, in the developed countries of Europe and North America, the major health concern is non-communicable diseases, especially those linked to obesity such as coronary heart disease, hypertension, diabetes and some cancers. While communicable diseases will remain a major problem, non-communicable diseases are a growing issue in many countries in Africa, and the WHO predicts that without the introduction of appropriate preventive action, non-communicable diseases will become a greater problem by $2030 .^{1}$ While there is evidence that programmes providing regular physical exercise and advocating a controlled diet can reduce obesity levels and the prevalence of the associated non-communicable diseases, health education leading to changes in people's attitudes and behaviours remains the best approach for reducing the problem of communicable diseases. ${ }^{1-6}$ Therefore, programmes that deliver health education and physical activity offer great potential for addressing the issues of communicable and non-communicable diseases.

Since 1994, FIFA's Medical Assessment and Research Centre (F-MARC) has been committed to the research aimed at improving the long-term, as well as the short-term, health prospects of football players of all levels of skill in differing environments around the world. ${ }^{7}$ In 2006, F-MARC embarked on a new challenge by moving the focus of its research from 'Medicine for Football' to 'Football for Health': the main objectives being to use the popularity of football to encourage greater physical activity among all age groups and to deliver health education to children in developing countries. As a medical legacy for the FIFA World Cup 2010 South Africa, F-MARC developed the '11 for Health' programme - a football-based health-education programme for children. '11 for Health' consists of 11 simple messages designed to address the most common risk factors for communicable and non-communicable diseases. These messages are linked to football themes and skills and are delivered in 11 football-based sessions. The success of the programme was demonstrated in studies in South Africa, Zimbabwe and Mauritius. ${ }^{89}$

When reporting intervention studies of this type in the scientific literature, the authors are normally required to focus on the descriptions of the sample population, data collection procedures, results, statistical analyses and the conclusions obtained from the studies. ${ }^{10}$ In most cases, this is fully justified because the primary purpose of the research is to demonstrate the efficacy, effectiveness and efficiency of the intervention. However, for novel interventions, a wider discussion of the planning and operational issues used to deliver such programmes could be beneficial to other researchers contemplating similar or related studies. The intention of this paper is therefore to bridge this gap by providing the authors' insights and perspectives on the aspects of the organisation and planning used for a nationwide implementation of the ' 11 for Health' football-based educational programme, using the project in Mauritius as an example.

\section{DISCUSSION}

The '11 for Health' programme was originally developed, implemented and evaluated in a pilot study in South Africa ${ }^{8}$ using the WHO's ${ }^{11} 10$-stage model for AIDS health promotion programmes: this model advocates establishing goals, conducting an initial assessment, targeting audiences, setting targets, establishing strategies for messages 
and materials, establishing strategies for channels of communication, providing support services, monitoring and evaluation, establishing budgets and conducting a reassessment. The pilot study in South Africa produced positive outcomes in terms of the gains in children's health knowledge postintervention: a $14 \%$ absolute increase across the health messages equivalent to a $26 \%$ relative increase on the baseline knowledge level. ${ }^{8}$ Moving from this pilot study to the larger nationwide project in Mauritius meant that additional concepts, such as the individual, organisational and social dimensions of the health promotion, ${ }^{12}$ and additional implementation issues, such as project aims and objectives, organisation, planning, implementation and monitoring, had to be considered. In addition, for the intervention to have longevity, it was essential to take into account the sustainability beyond the research phase. The following sections discuss these topics in the context of delivering the ' 11 for Health' programme to 400 first-year secondary school children during a pilot study followed by the national implementation involving 17 000 children. Research results obtained with the ' 11 for Health' programme have been published separately ${ }^{8}$ and these publications should be consulted for other aspects of the programme, including the detailed results.

\section{Aims and objectives}

The aim of the project was to raise awareness and knowledge of communicable and non-communicable diseases that had been identified as important health issues by the Mauritius Ministry of Health; this enabled health issues identified upstream by national bodies to be addressed downstream among schoolchildren in Mauritius. ${ }^{13}$ In order to achieve the project aim, specific objectives were defined, such as the programme should be

- scalable to enable national implementation;

- capable of implementation by community-based educators, such as schoolteachers, football coaches and nongovernment organisation workers;

- acceptable to government departments of health and education;

- sustainable through capacity-building of local stakeholders.

These objectives impacted strongly on the considerations given to the development and management of the ' 11 for Health' project in Mauritius. For example, it is possible to develop interventions that will be successful in specific communities at specific points in time but which will almost certainly fail as soon as the researchers are no longer available to provide the necessary expertise and support to the local community. The focus of small, local implementations is often to demonstrate efficacy and effectiveness, which may not be the only relevant issues for delivering health promotion programmes on a national level; for example, many models emphasise the importance of building capacity within the community. ${ }^{3}$

\section{Organisation}

Establishing an appropriate organisation and allocating resources for a project are inextricably linked to the aims, objectives and implementation strategy adopted for the project. While the three authors were involved in developing the '11 for Health' programme and each provided critical input to all aspects of the project, the scope and size of this project meant that it was necessary to assign lead responsibilities for various aspects of the project to each of the authors, namely
Project direction (J.D.)

Developing a long-term strategy for the direction and implementation of the ' 11 for Health' programme within Mauritius; liaising with FIFA management to agree funding requirements; contacting and meeting with the President and Secretary General of the Mauritius Football Association (MFA) to confirm the principles of collaboration; contacting and meeting with Mauritius Government Ministers of Health, Education and Sport to confirm the principles of collaboration; developing an ongoing strategy for implementing the ' 11 for Health' programme in other African countries and other continents.

\section{Administration (A.J.)}

Writing and adapting the project proposal; meeting and recruiting collaborators within the MFA; establishing formal budgets and contracts with the MFA; communications within FIFA; confirming the availability of appropriate personnel for delivering the interventions; reaching agreements on resource requirements and delivery of these resources to the MFA and participating schools; liaising with the Secretary General of the MFA and the local coordinator to ensure compliance with contractual and financial agreements.

\section{Implementation (C.W.F.)}

Preparing a programme manual and country-specific '11 for Health' project; obtaining ethics approval for the study from the Mauritius Ministry of Health; preparing teacher-training courses for the implementation of the programme; inspecting standards and facilities available at schools; preparing data collection instruments; writing job specifications for local collaborators; liaising with the local coordinator, who was responsible for the local logistics required for implementing the training course, recruiting and liaising with schools during implementation of the programme, ensuring compliance with programme delivery and data collection; and data analysis.

\section{Planning}

Following an enquiry from the MFA to implement the " 11 for Health' programme in Mauritius, a project proposal, outlining the programme philosophy and including the local organisation and resources required, was sent to the MFA with a request for a written response showing how each of the specific requirements could be delivered. The MFA submitted a formal reply to F-MARC detailing the resources and expertise available to the MFA together with confirmation that the project would have the support of the Mauritius Government. After reviewing the submission, members of F-MARC held talks with Ministers from the Departments of Health, Education and Sport and the MFA's General Secretary in order to formalise a budget and agree working arrangements. An ethics application for the study was prepared and submitted to the Mauritius Ministry of Health for approval; the Minister for Education provided an approval for the programme to be implemented within the school curriculum and the Minister for Sport seconded a member of its staff to the MFA to act as the local coordinator, who liaised with F-MARC and government departments.

It was recognised early in the planning process that compliance with project timescales would be a critical factor because training courses and school implementations had to be held within limited timeframes to fit with school-term times, examination periods and other scheduled school activities. A pilot project involving 400 first-year secondary school children at 11 schools was implemented initially in order (1) to assess the efficacy of the programme in Mauritius, (2) to identify the local 
implementation issues and (3) to determine the organisational and resource requirements needed for delivering the " 11 for Health' programme nationally in Mauritius. After the successful completion of the pilot study, ${ }^{9}$ further discussions were held with the MFA and the Ministries of Health, Education and Sport to explore the organisational implications associated with implementing the project nationwide to 17000 schoolchildren within $\sim 200$ schools, as this would require training and liaising with 400 teachers.

\section{Implementation}

Following discussions with local stakeholders, F-MARC developed an implementation protocol for delivering the "11 for Health' programme in Mauritius. This included (1) preparation of a programme manual; (2) arrangements for teachers' training courses and (3) a time schedule for delivering the teachers' training courses, the interventions and the pre and postcourse programme evaluation questionnaires. The local coordinator seconded from the Department of Sport and based within the MFA provided a key role in the schools' implementation, as he developed the lines of communication with F-MARC, the Ministry of Education and school principals and teachers. In order to progress from a relatively small pilot study to a national implementation, it was recognised that there was an essential need to develop skills and to expand capacity to deliver the ' 11 for Health' programme within Mauritius. It was felt important to engender a belief in the philosophy of the programme among the schoolteachers leading to their ownership of the programme's aims and objectives in order to achieve sustainability.

\section{Pilot project}

Schools were recruited to the project following discussions between the local coordinator and school principals and assessment visits by F-MARC. Teachers from the participating schools together with football coaches from the MFA were taken through a 5-day interactive training course by F-MARC; this course (1) provided participants with a detailed programme manual that itemised and described each aspect of the programme; (2) outlined the programme's health-enhancing philosophy of physical activity linked with health education; (3) demonstrated the football skills and discussed the health knowledge associated with each session of the programme; (4) discussed the presentational skills required to deliver the "11 for Health' programme in an entertaining but informed way to 11-12-year-old children; (5) explained the procedures for delivering the precourse and postcourse evaluation questionnaires; (6) tested participants' ability to deliver sessions using a series of teach-backs and (7) provided all teachers with the resources required to deliver the programme. During the delivery of the '11 for Health' programme within the schools, the local coordinator was responsible for ensuring that the programme remained on schedule at each school and provided support to the teachers in order to address any local implementation issues.

Following the successful completion of the pilot study, the MFA arranged a graduation ceremony for all the children and teachers who took part in the ' 11 for Health' pilot study: representatives from F-MARC and the Ministries of Health, Education and Sport also attended this graduation. The ceremony received widespread media coverage within Mauritius, which helped to broaden the awareness and acceptance of the programme in readiness for the delivery of the nationwide project.

\section{Nationwide project}

Detailed preparations for the nationwide implementation began after the graduation ceremony was held for the pilot study. Further discussions within the Ministries of Health, Education and Sport confirmed their continued support for a nationwide implementation of the programme to all first-year secondary school children. Following these meetings, a local organisation was established that could oversee and ensure the delivery of a successful project to 17000 children studying in 200 schools. Two 'zone leaders' (North and South of the country) were recruited to work with the local coordinator at the MFA; their role was to liaise with four physical education area organisers working within the Ministry of Education and to act as the MFA link with the schools. Discussions were also held with the organisation representing the private secondary schools in Mauritius, as these schools also took part in the nationwide intervention. Following a review of the pilot study and discussions with the Ministry of Health, it was decided to replace the session relating to malaria with a new session focusing specifically on diabetes, as this was considered by the Ministry of Health to be a greater concern within the country.

A cascade approach was adopted for training the large number of teachers required for the nationwide implementation. The teachers involved in the original pilot study attended a 5 -day refresher-training course run by F-MARC: these teachers then delivered the 5-day training course, over the next 2 weeks to the new teachers joining the nationwide project at three regional locations in Mauritius and in one further training course for teachers working on the island of Rodrigues, which is part of the Republic of Mauritius. During the delivery of the ' 11 for Health' programme within the schools, the local coordinator, two zone leaders and four physical education area organisers played important roles in achieving a successful outcome to the project.

The nationwide project was launched at a public ceremony involving representatives from F-MARC and the Ministries of Health, Education and Sport in order to increase public awareness of the project. Finally, following a successful implementation, a graduation ceremony for the nationwide project was held; this was attended by representatives of the schools and children taking part, the President of the Republic of Mauritius together with the representatives of his Ministries of Health, Education and Sport and the members of F-MARC who had lead the project from its inception.

\section{Materials used to support the pilot and nationwide projects}

In addition to providing the overall project management and financial support for the pilot and nationwide projects, F-MARC provided other support materials to each teacher, such as

\section{Programme manual}

A manual that supported the training course and that also provided teachers with a summary of (1) the skills required to deliver the programme, (2) the content of each of the 11 sessions, (3) the timings for each aspect of each session and (4) health information sheets that contained additional information to support the teachers when answering children's questions during session discussion periods.

\section{Activity Cards}

A set of A5 size laminated activity cards, as most sessions used activity cards to highlight issues related to the session's health topic. 


\section{Equipment}

Footballs, cones, bibs, stopwatch and whistle, to implement the interactive games in each session.

\section{Questionnaires and attendance record}

Copies of the health knowledge questionnaire and an attendance record to evaluate the project.

\section{Football ambassadors}

Ten international footballers, with an emphasis on players from Africa, and one international team manager provided high-profile support for the 11 health messages. Each ambassador was associated with one of the football activity/health topic combinations: players produced a video clip, which showcased their skills in the football activity and provided a personal message supporting the health topic. The 11 video clips produced were made available on the FIFA web pages, ${ }^{14}$ and they were also amalgamated into a composite video, which was made into a DVD that was provided to each of the schools. Each of the individual clips was also shown on the pitch advertising boards during each match in the 2010 FIFA World Cup in South Africa.

\section{Monitoring'}

The efficacy of the ' 11 for Health' pilot and nationwide projects was assessed using a series of questionnaires, including (1) the teachers' evaluation of the training course; (2) children's pre and postintervention health knowledge; (3) children's attendance on the programme and (4) children's overall assessment of the ' 11 for Health' programme. Whenever feasible, the questionnaires were implemented by someone who was not directly involved in the delivery of the ' 11 for Health' sessions in order to minimise the possibility that the children's responses to questions could be influenced by the teachers. For the pilot study, questionnaire data were recorded by F-MARC but because of the number of children involved, administrators based at the MFA recorded data obtained from the nationwide project: a proportion of the data entry was audited for accuracy by F-MARC. Data analyses for the pilot and nationwide projects were completed by F-MARC.

\section{Sustainability}

A key objective of the project was to create an intervention that could become self-sustainable within the country and this intention was reflected in the programme implementation strategy. It was recognised early in the development of the project that the way to achieve sustainability was through a cost-effective ${ }^{1}$ approach using a tripartite strategy involving F-MARC, the country's Football Association and the appropriate government departments. It was therefore considered essential that the project should be implemented in a way that would transfer skills and knowledge to stakeholders in the country involved. In this respect, staff within the MFA acquired expertise and skills that could be used not just to deliver the ' 11 for Health' programme but which could also be applied to other projects within the Football Association; government departments experienced what could be achieved through close collaboration with a national organisation, and this will be beneficial for the country beyond the ' 11 for Health' programme. F-MARC will provide a reduced level of support in Mauritius in the 2 years beyond the first nationwide implementation in order to provide an ongoing support to the MFA and government as the programme becomes absorbed permanently into the school curriculum. This ongoing support will provide F-MARC with valuable information about the issues involved in transferring the ownership of the '11 for Health' programme to national bodies.

\section{CONCLUSIONS AND FUTURE DIRECTIONS}

The pilot study produced an $18 \%$ absolute increase in postintervention health knowledge across the health messages, which was equivalent to a $26 \%$ relative increase against the children's baseline knowledge level; 9 while the nationwide study produced a $14 \%$ absolute increase in the postintervention health knowledge across the health messages, equivalent to a $22 \%$ relative increase against the baseline knowledge level. The implementation of the ' 11 for Health' programme was considered to have met the objectives set out at the beginning of the project and, importantly, was considered to be a success by F-MARC, the MFA and the Mauritius Government Departments of Health, Education and Sport. An independent assessment ${ }^{15}$ of the development and implementation of FIFA's 'Football for Health' philosophy, which includes the '11 for Health' programme, concluded that it fulfilled all eight components of Kotter's model ${ }^{16}$ for strategic change. The intention is for the implementation of the programme to continue in Mauritius for a further 2 years, at which time the long-term success and ramifications of the implementation will be evaluated. The strategy used to implement the ' 11 for Health' programme in Mauritius has already been transferred to three other African countries (Botswana, Malawi and Namibia), namely a tripartite collaboration between FIFA/F-MARC, the country's Football Association and the Government Departments of Health, Education and Sport with the country's media used to increase the public awareness of the programme. In Namibia, the pilot study phase has been completed and planning is underway for a nationwide implementation. In Botswana and Malawi, training courses have been completed and pilot studies are underway; in both of these countries, the intention, if the pilot studies are successful, is to implement nationwide interventions. Importantly, experienced ' 11 for Health' teachers from Mauritius were used to run the training courses in Botswana, Malawi and Namibia; it is envisaged that this cascade approach will be adopted further as the programme is delivered in other African countries.

The concept of the ' 11 for Health' programme was presented to the 2009 FIFA Congress and the results of the pilot studies in South Africa, Zimbabwe and Mauritius to the 2010 FIFA Congress. Following the 2011 FIFA Congress, the Mexican and Colombian Football Federations approached F-MARC to use the 2011 FIFA U-17 World Cup and 2011 FIFA U-20 World Cup as the starting points for pilot studies of the ' 11 for Health' programme prior to nationwide projects in these countries. The '11 for Health' manual has been translated into Spanish and

\section{What this study adds}

- An outline of the planning and organisational requirements involved in implementing a nationwide physical activity and health-education programme for children.

- A description of the stakeholder involvement required for achieving sustainability of a nationwide school-based physical activity and health-education programme.

- A review of the resources and management expertise required to implement a nationwide physical activity and health-education programme. 
planning is at an advanced stage for stepwise implementations in Mexico and Colombia. Additionally, Spanish-speaking footballers, who were recruited to be used as ambassadors, have produced videos to support the health messages in these countries. Further discussions are underway to commence pilot studies of the ' 11 for Health' programme in two Pacific Islands and in Brasil in connection with the 2014 World Cup Brasil. The ' 11 for Health' programme, which is based on the popularity of football and 11 simple health messages, is therefore developing into a global health promotion programme.

Contributors JD: researcher on the ' 11 for Health' project in Mauritius; contributed to the structure of this paper; reviewed the draft paper; edited and approved the final text. CF: researcher on the ' 11 for Health' project in Mauritius; contributed to the structure of this paper; prepared the draft paper; edited and approved the final text. AJ: researcher on the '11 for Health' project in Mauritius; contributed to the structure of this paper; reviewed the draft paper; edited and approved the final text.

Acknowledgements The authors would like to acknowledge the invaluable support provided by Cadrivel Dorasami and Ananda Vuddamalay from the Mauritius Football Association during the implementation of the pilot and nationwide '11 for Health' projects in Mauritius.

Competing interests None.

Provenance and peer review Not commissioned; externally peer reviewed.

\section{REFERENCES}

1. World Health Organisation. Global Status Report on Non-communicable Diseases 2010. Geneva: WHO 2010.

2. Nyamwaya D. Health Promotion: a tool for fostering comprehensive health development agendas in the African region. WHO African Health Monitor 2008;8:24-7.
3. US Department of Health and Human Services. Theory at a Glance: A Guide for Health Promotion Practice. Second edition. Washington, DC: US Department of Health and Human Services 2005.

4. Christodoulos AD, Douda HT, Polykratis M, et al. Attitudes towards exercise and physical activity behaviours in Greek schoolchildren after a year long health education intervention. Br J Sports Med 2006;40:367-71.

5. Hills AP, Andersen LB, Byrne NM. Physical activity and obesity in children. Br J Sports Med 2011;45:866-70.

6. Maro CN, Roberts GC, Sørensen M. Using sport to promote HIV/AIDS education for at-risk youths: an intervention using peer coaches in football. Scand J Med Sci Sports 2009;19:129-41.

7. Fuller CW, Junge A, Dvorak J. Risk management: FIFA's approach for protecting the health of football players. Br J Sports Med 2012;46:11-17.

8. Fuller CW, Junge A, DeCelles J, et al. 'Football for Health'-a football-based health-promotion programme for children in South Africa: a parallel cohort study. Br J Sports Med 2010;44:546-54.

9. Fuller CW, Junge A, Dorasami R, et al. '11 for Health', a football-based health education programme for children: a two-cohort study in Mauritius and Zimbabwe. Br J Sports Med 2011;45:612-18.

10. BMJ. Manuscript format. http://group.bmj.com/products/journals/instructionsfor-authors/formatting/ (accessed 27 October 2011).

11. World Health Organisation. Guide to Planning Health Promotion for AIDS Prevention and Control. Geneva: WHO 1989

12. McLeroy KR, Bibeau D, Steckler A, et al. An ecological perspective on health promotion programs. Health Educ 0 1988;15:351-77.

13. Gehlert S, Sohmer D, Sacks T, et al. Targetting health disparities: a model linking upstream determinants to downstream interventions. Health Affairs 2008;27:339-49.

14. FIFA. Football for Health. https://extranet.fifa.com/medical/en/Football-ForHealth/ (accessed 27 October 2011)

15. Langton N, Khan KM, Lusina SJ. FIFA's Football for Health: applying Kotter's eight-step programme for transformational change to a mass participation activity. Br J Sports Med 2010;44:537-9.

16. Kotter JP. Leading change: why transformation efforts fail. HBR 2007:96-103. 